\title{
Crack resistance of bismuth ferrite films obtained on a flexible substrate
}

\author{
Shikhgasan Ramazanov ${ }^{1}$, Ştefan Țălu ${ }^{2, *}$, Dinara Sobola ${ }^{3,4}$, Farid Orudzev ${ }^{1}$, Guseyn \\ Ramazanov $^{5}$, Daud Selimov ${ }^{1}$, Pavel Kaspar ${ }^{4}$, Robert Mackü ${ }^{4,6}$, and Anton Nazarov ${ }^{7}$ \\ ${ }^{1}$ Dagestan State University, Makhachkala, St. M. Gadjieva 43-a, Dagestan Republic, 367000, Russia \\ ${ }^{2}$ The Technical University of Cluj-Napoca, Constantin Daicoviciu Street, no. 15, Cluj-Napoca, \\ 400020, Cluj county, Romania \\ ${ }^{3}$ Institute of Physics of Materials, Academy of Sciences of the Czech Republic, Žižkova 22, Brno 616 \\ 62, Czech Republic \\ ${ }^{4}$ Brno University of Technology, Faculty of Electrical Engineering and Communication, Department \\ of Physics, Technicka 2848/8, Brno 61600, Czech Republic \\ ${ }^{5}$ Dagestan State Technical University, Makhachkala, St. I. Shamil, 70, Dagestan Republic, 367026, \\ Russia \\ ${ }^{6}$ Brno University of Technology, Central European Institute of Technology, Purkyňova 123, 61200 \\ Brno, Czech Republic \\ ${ }^{7}$ Ural State University of Economics, Institute of management and information technologies, Russian \\ Federation
}

\begin{abstract}
Ultrathin $\mathrm{BiO}_{x}$ and $\mathrm{FeO}_{x}$ layers were obtained by Atomic Layer Deposition (ALD) on the surface of a flexible Kapton substrate (poly (4,4'oxydiphenylene-pyromellitimide)) at a temperature of $250{ }^{\circ} \mathrm{C}$. The layer thickness was $50-100 \mathrm{~nm}$. Surface morphology, electrical polarization, and mechanical properties were investigated by Atomic Force Microscope, Piezoelectric Force Microscopy and Force Modulation Microscopy. Chemical analysis was performed by X-ray Photoelectron Spectroscopy, where the formation of $\mathrm{Bi}_{2} \mathrm{O}_{3}$ and $\mathrm{Fe}_{2} \mathrm{O}_{3}$ phases, as well as intermediate phases in the $\mathrm{Bi}-\mathrm{Fe}-\mathrm{O}$ system, was observed. With a small increase in the Bi content of the film, the BFO / Kapton structure becomes more crack resistant. Modification of the Kapton surface with bismuth and iron oxides showed that such a composition exhibits multiferroic behavior.
\end{abstract}

\section{Introduction}

Kapton (poly (4,4'-oxydiphenylene-pyromellitimide)) was used as substrates for the growth of an amorphous film in the Bi-Fe-O system. It is stable over a wide temperature range from -273 up to $+400{ }^{\circ} \mathrm{C}$.

Bismuth ferrite $\left(\mathrm{BiFeO}_{3}\right.$ or just $\left.\mathrm{BFO}\right)$ has become an important and widely used material in the field of multiferroics, because of its useful properties. Some of the more important among them is coupled magnetic ordering, giving it both ferroelectric and antiferromagnetic properties, including large remnant ferroelectric polarization, potentially

\footnotetext{
* Corresponding author: stefan_ta@yahoo.com
} 
greater than other commonly used ferroelectric materials [1-3]. When the absence of lead and the ability to keep its properties in room temperature and very thin films (in the range of units of nanometers), are added into the consideration, BFO shows its incredible potential for ferroelectric, magnetoelectric, and piezoelectric applications [4-6].

One of the main challenges in working with BFO films is preparation of the film and selection of suitable substrate. There are several working deposition methods, all with their own capabilities and limitations, like molecular beam epitaxy (MBE), metal-organic vapor deposition (MOCVD) and pulsed layer deposition (PLD) [7], but these all struggle when trying to deposit a uniform and precisely detailed thin layer of BFO at low temperatures. The only method that is able to clear all these requirements is atomic layer deposition (ALD) [8-12], which is the reason why it is used to prepare BFO layers in this paper.

There are many substrates which BFO film can be deposited on, for example silicon or carbon, and these substrates can be used to great effect, when a specific goal is in mind [13], but to preserve the overall properties while increasing flexibility, a different substrate was required. The use of polymeric materials to modify the properties of bismuth ferrite and create hybrid materials based on it allows one to combine the mechanical superiority of polymeric materials (flexibility) and the electromagnetic properties of multiferroic. Such polymers as polyaniline (an example of a conductive semiconductor) or polyvinylidene fluoride (a piezopolymer) began to be widespread at modern technologies [14-16]. The use of strong mechanical stresses, as well as the introduction of dopants (which is a way of creating mechanical stresses at the level of the crystalline lattice), can destroy the spatially modulated structure.

Polyimide Kapton is a material developed by DuPont company, with many interesting properties. It mostly takes shape of a tape or a thin film covered laminated with other materials or without any lamination. The material takes a form of polymerized aromatic dianhydride with aromatic diamine [17].

It was noted in [18] that the surface can also change due to adding of chemical elements in BFO. The morphology changes with a change in the composition of the bismuth ferrite films, and, most likely, a change in the phase ratio can also change the hardness of the resulting films.

Preparation of functional oxides on flexible substrates is on of the great technological challenges because of this film's brittleness. There are several approaches for preparation of the flexible structures, among them are heteroepitaxy on organic or inorganic flexible substrates [19], and epitaxial lift-off [7]. The epitaxial lift-of advance is possible growth of structurally perfect film. The oxide film than separated by removing from sacrifice layer between the film and substrate. This approach is more technologically complicated in comparison with heteroepitaxy. Thus, the mechanical properties of flexible structures based with BFO thin films can be controlled by adding dopants and changes in composition.

\section{Experimental Details}

The films of Bi-Fe-O composition were prepared by atomic layer deposition (ALD) at ALDCERAM ML-200 device. Samples were obtained by layer-by-layer growth of BiOx and FeOx, a similar experiment was performed on HOPG substrates. The source for bismuth component was $\mathrm{Bi}(\mathrm{mmp})_{3}($ (Tris(1-methoxy-2-methyl-2-propoxy) bismuth, SigmaAldrich)). Ferrocene was the source of iron $\left(\mathrm{Fe}\left(\mathrm{C}_{5} \mathrm{H}_{5}\right)_{2}\right.$, Sigma-Aldrich).

The experiment was repeated similarly to obtain thin films of bismuth ferrite on the surface HOPG $[20,21]$ and $\mathrm{TiO}_{2}[22,23]$. Figure 1 shows optical images of the surface of the obtained films, depending on the increase in the concentration of bismuth in the film: sample 1 is a stoichiometric composition, sample 2 contains a slight higher concentration of bismuth. 
a)
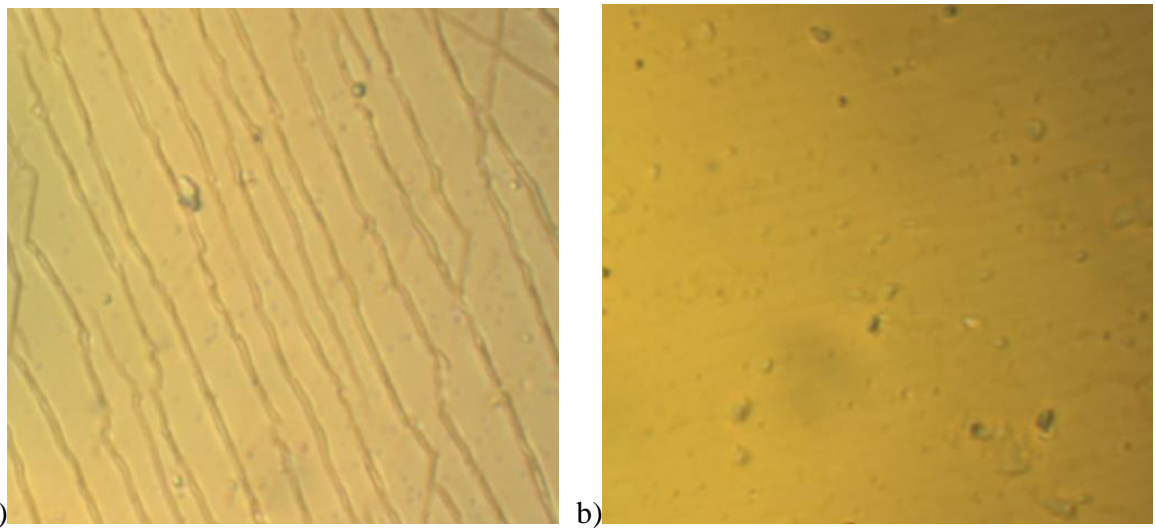

Fig. 1. Optical images of the BFO/Kapton surface: a) sample 1, b) sample 2 .

As can be seen from Figure 1, with an increase of the bismuth content in the BFO phase, the BFO/Kapton structure becomes more elastic and, accordingly, it is more crackresistant when bent.

\section{Results and Discussion}

The tape was placed on silicon wafer as support material. The study of chemical conditions of the surface was made by XPS (AXIS SupraTM).

XPS allows us to suggest that in the second case, bismuth is less oxidized and selforganizing, agglomerating into metallic inclusions (Figure 2). The presence of more dangling oxygen bonds is greater in the second sample, which means larger amorphousness. This effect creates an excess of oxygen. A consequence of the excess oxygen on the sample is the broadening of the peak of iron. Also, in the first case, the $\mathrm{Fe}_{3} \mathrm{O}_{4}$ and $\mathrm{Bi}_{2} \mathrm{O}_{3}$ phases are also formed on the surface of the sample. This is a more favorable combination for the subsequent formation of the bismuth ferrite phase, taking into account the evaporation of bismuth during heating and a decrease in oxygen concentration during annealing in vacuum.

a)

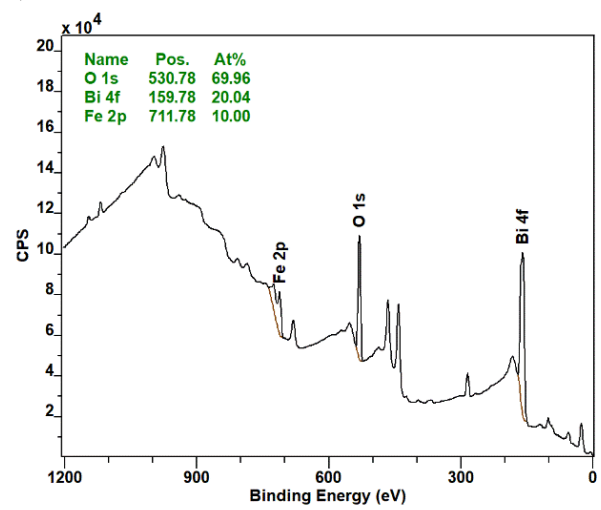

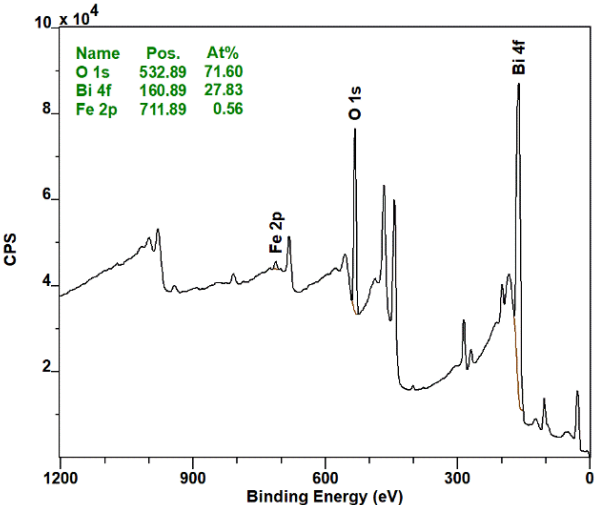


b)
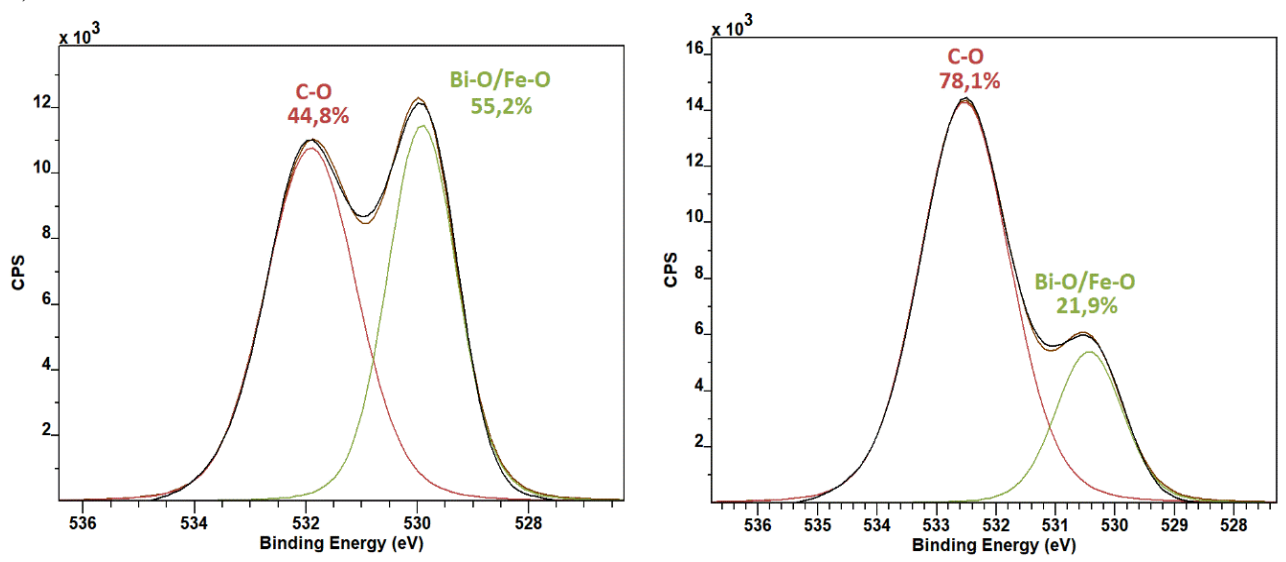

Fig. 2. XPS survey spectra (a) of two samples $\mathrm{Bi}_{1+\mathrm{x}} \mathrm{FeO}_{3}$ (left $\mathrm{x}=0$, right $\mathrm{x}>0$ ) and (b) corresponding O1s detailed spectra (left $x=0$, right $x>0$ ).

The contribution to the film morphology is made by both the chemical composition of the substrate and its structure [8,11, 24-26].

Kapton was chosen because of the possibility of its use after treatment in the field of terahertz radiation as an absorbent [12]. It is known that Kapton, like most polymers, can interact with atomic and ionized oxygen. The authors of [13] used silica films as a protective Kapton film that protects from degradation.

In our case, the property of interaction with oxygen is a decisive factor in the formation of the film-substrate interface. The use of Kapton allows the study of mechanical deformations and film tension due to the flexibility of the substrate.

Kapton has suitable chemical, mechanical, electrical, and temperature properties for use as active material substrates [17].

Atomic force microscopy (AFM) images (Figure 3) show the presence of nanoscale features on the surface of the $\mathrm{Bi}-\mathrm{Fe}-\mathrm{O} /$ Kapton structure. Different topography is mainly caused by organization of bismuth on the surface.

In comparison with other techniques of surface imaging (scanning electron microscopy or optical methods) AFM is more reliable for 3D analysis of the surface topography or modification of the surface with precise values of Z-axis [27-31].

In addition to topography with real values of heights, AFM has a number of modes that make possible studying the electrical and mechanical properties of materials [32-35].

This technique is proved to be reliable for characterization of surface at various degradation and damaging processes [36-39].

The use of scanning microscopy of the piezoelectric response (PFM) provides information about piezoelectric domain organization on the surface [40, 41].

The PFM measurements were carried out by Scanning Probe microscope NTEGRA Prima (NT-MDT, Russia) using conductive tip with $\mathrm{W}_{2} \mathrm{C}$ coating. The same probe was used for Force Modulation Mode measurement. This mode provides qualitative distribution of the hardness. Signal of these polarization domains on the presented samples is fairly weak, but still within the detection range. Figure 3 shows the topography and phase contrast at bias voltage of $10 \mathrm{~V}$. 


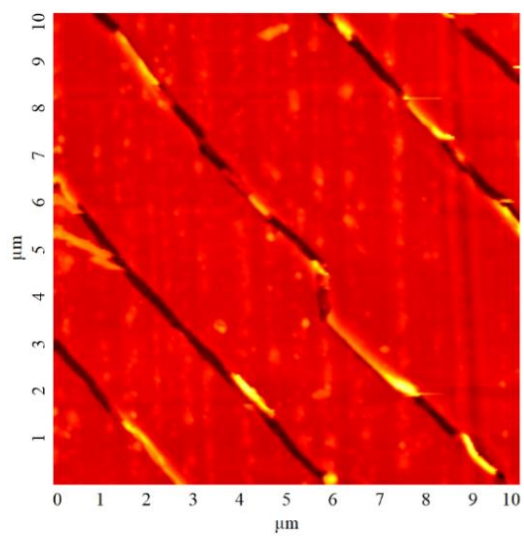

(a)

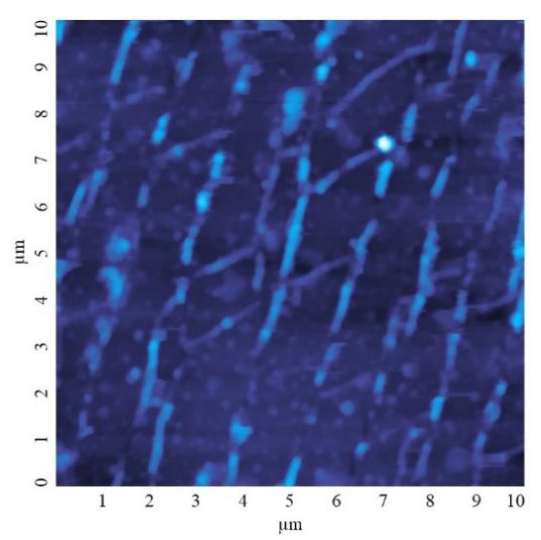

(c)

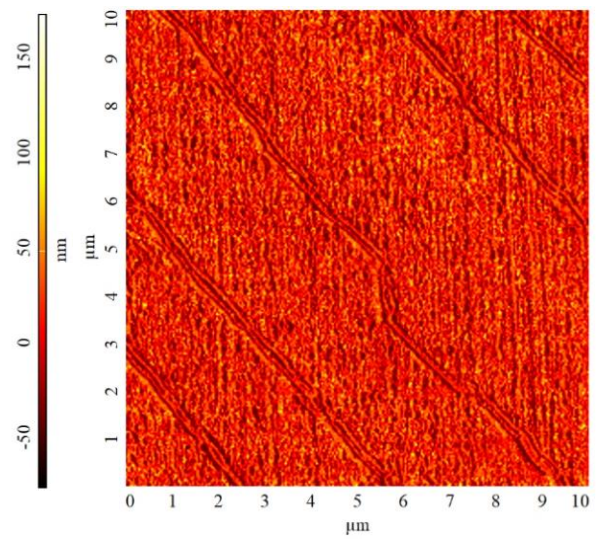

(b)
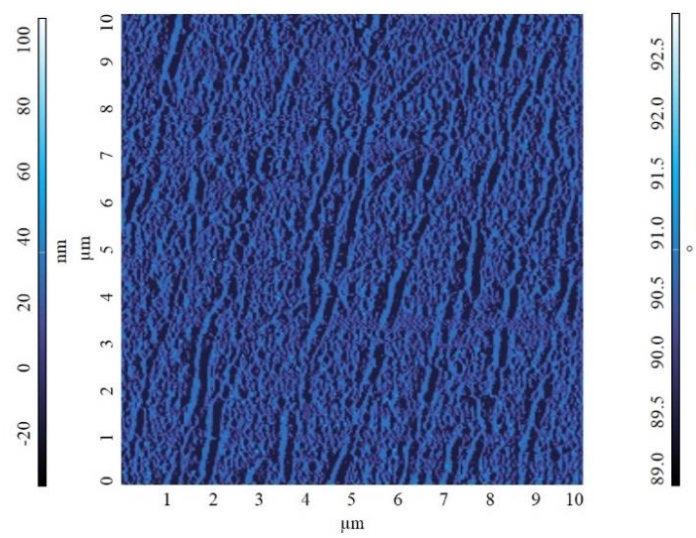

(d)

Fig. 3. Topography and PFM phase contrast a, b) sample 1 and c, d) sample 2. Scan area $10 \times 10 \mu \mathrm{m}^{2}$.

Force modulation microscopy (FMM) measures the elasticity of the sample and can provide a contrast between different neighboring materials of different stiffness. As a part of AFM, it uses a cantilever to scan the surface and to detect the deflection constant. While the cantilever scans, it is oscillated up and down by a piezoelectric signal, so that the tip of the probe indents slightly into the surface of the scanned sample. The measure of indentation then provides the information about hardness of the sample inversely. The hardness was studied at several points and the most common images are shown in Figure 4.

Measurement on both samples yielded similar small phase shifts at PFM images (Figure $3 \mathrm{~b}, \mathrm{~d})$. It appears that PFM is either independent on measured magnetic properties, or the piezo effect is beyond the sensitivity of the device. Hardness on microscale was studied using the same tip and FMM results (Figure $4 \mathrm{~b}, \mathrm{~d}$ ) correspond with morphology measurements (Figure 4 a, c). Larger FMM response belongs to Sample 1 (Figure 4 a, b), which also means that Sample 1 is harder than Sample 2. 


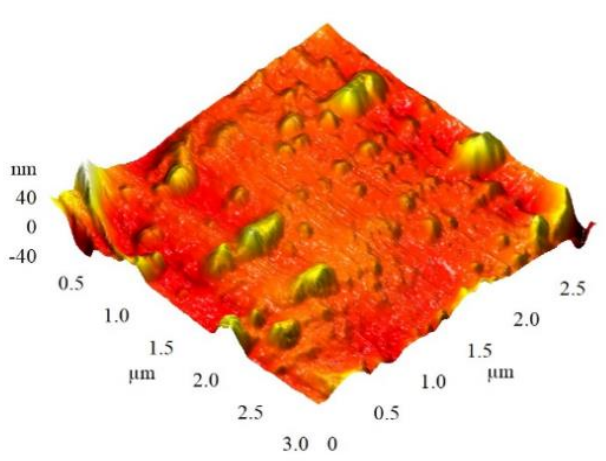

(a)

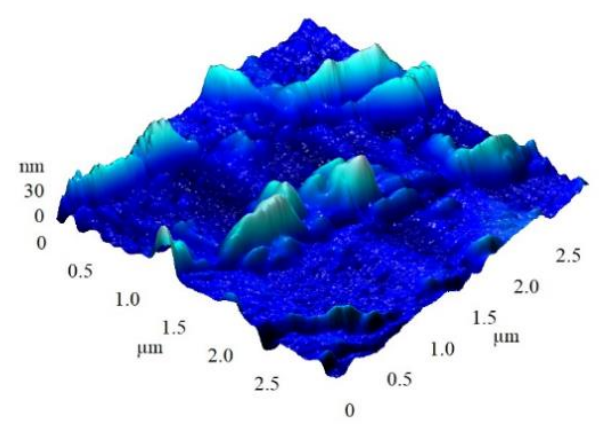

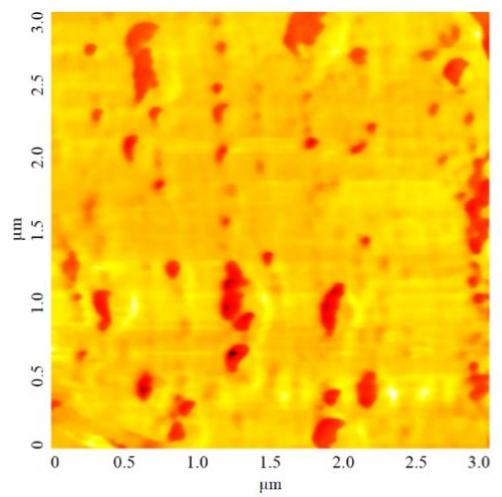

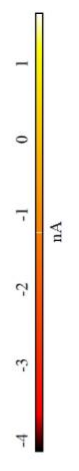

(b)

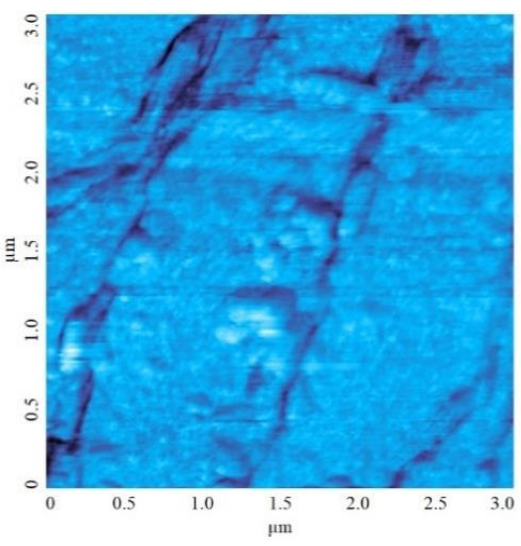

Fig. 4. Topography and FMM image a, b) sample 1 and c, d) sample 2. Scan area $3 \times 3 \mu \mathrm{m}^{2}$.

Harder material does not allow bending as much as the softer variant, and thus gives the material fewer opportunities to form breaks. Ultimately, we can confirm that hardness of the films can be controlled using different ratio of Fe and Bi during ALD. It defines difference at magnetic response, which is higher with larger amount of Fe. At the same time, the harder material provides lower amounts of cracks during manipulation with the film on flexible substrate.

\section{Conclusion}

This work describes the importance of flexible substrates like Kapton in design of structures for electronics. ALD synthesis procedure of $\mathrm{Bi}-\mathrm{Fe}-\mathrm{O}$ thin film on Kapton was presented. The structure and composition of the films was characterized using XPS. An analysis of the topography of the films contributes to the development of a theoretical base explaining the principles of the film preparation by the ALD method of hybrid materials.

The results contribute to the improvement of reproducibility of the required structures and physical properties of the films. It was found that the magnitude of the FMM signal correlates with the fracture characteristics of a complex flexible material due to its resistance to bending when the stoichiometry of the film composition deviates towards an 
increase in the bismuth concentration. The results contribute to the improvement of reproducibility of the required structures and physical properties of the films.

CzechNanoLab project LM2018110 funded by MEYS CR is gratefully acknowledged for the financial support of the measurements/sample fabrication at CEITEC Nano Research Infrastructure.

\section{References}

1. A. Bedoya-Pinto, M. Donolato, M. Gobbi, L.E. Hueso, P. Vavassori, Appl. Phys. Lett., 104, 062412 (2014)

2. E. Lindner, V.V. Cosofret, S. Ufer, R.P. Buck, R.P. Kusy, R.B. Ash, H.T. Nagle, J. Chem. Soc. Faraday Trans., 89, 361 (1993)

3. F. Orudzhev, S. Ramazanov, D. Sobola, N. Alikhanov, V. Holcman, L. Škvarenina, P. Kaspar, G. Gadjilov, Sensors, 20, 6736 (2020)

4. J.O. Simpson, A.K. St. Clair, Thin Solid Films, 308-309, 480, (1997)

5. S. Ramazanov, D. Sobola, F. Orudzhev, A. Knápek, J. Polčák, M. Potoček, P. Kaspar, R. Dallaev, Nanomaterials, 10, 1990 (2020)

6. M. Zhang, L. Liu, C. Zhang, IOP Conf. Ser.: Mater. Sci. Eng., 782, 022096 (2020)

7. D. Pesquera, E. Khestanova, M. Ghidini, S. Zhang, A.P. Rooney, F. Maccherozzi, P. Riego, S. Farokhipoor, J. Kim, X. Moya, M.E. Vickers, N.A. Stelmashenko, S.J. Haigh, S.S. Dhesi, N.D. Mathur, Nat Commun., 11, 3190 (2020)

8. N. Papež, D. Sobola, A. Gajdoš, L. Škvarenina, R. Macků, M. Eliáš, A. Nebojsa, R. Motúz, J. Phys.: Conf. Ser., 1124, 041015 (2018)

9. Ş. Ţălu, P. Nikola, D. Sobola, A. Achour, S. Solaymani, J. Mater. Sci. Mater. Electron., 28, 15370 (2017)

10. R. Shikhgasan, Ş. Ţălu, S. Dinara, S. Sebastian, R. Guseyn, Superlattices Microstruct., 86, 395 (2015)

11. N. Papež, D. Sobola, L. Škvarenina, P. Škarvada, D. Hemzal, P. Tofel, L. Grmela, Appl. Surf. Sci., 461, 212 (2018)

12. S. Venkatachalam, D. Bertin, G. Ducournau, J.F. Lampin, D. Hourlier, Carbon, 100, 158 (2016)

13. Y. Xie, Y. Gao, X. Qin, H. Liu, J. Yin, Surf. Coatings Technol., 206, 4384 (2012)

14. K. Castkova, J. Kastyl, D. Sobola, J. Petrus, E. Stastna, D. Riha, P. Tofel, Nanomaterials, 10, 1221 (2020)

15. A. Knápek, D. Sobola, D. Burda, A. Daňhel, K.M. Mousa, V. Kolařík, Nanomaterials, 91756 (2019)

16. P. Kaspar, D. Sobola, K. Částková, A. Knápek, D. Burda, F. Orudzhev, R. Dallaev, P. Tofel, T. Trčka, L. Grmela, Z. Hadaš, Polymers, 12, 2766 (2020)

17. M.A. Signore, A. Taurino, M. Catalano, M. Kim, Z. Che, F. Quaranta, P. Siciliano, Mater. Des., 119, 151 (2017)

18. Ş. Ţălu, A.S. Priya, D. Geetha, Microsc. Res. Tech., (2021). DOI: 10.1002/jemt.23783

19. Yanan Zhao, Renci Peng, Yunting Guo, Zhijie Liu, Yongqi Dong, Shishun Zhao, Yaojin Li, Guohua Dong, Yue Hu, Junwei Zhang, Yong Peng, Tiannan Yang, Bian Tian, Yifan Zhao, Ziyao Zhou, Zhuangde Jiang, Zhenlin Luo, Ming Liu, Adv. Funct. Mater. (2021). DOI: 10.1002/adfm.202009376 
20. S. Ramazanov, D. Sobola, F. Orudzhev, A. Knápek, J. Polčák, M. Potoček, P. Kaspar, R. Dallaev, Nanomaterials, 10, 1990 (2020)

21. D. Sobola, S. Ramazanov, M. Konečný, F. Orudzhev, P. Kaspar, N. Papež, A. Knápek, M. Potoček, Materials, 13, 2402 (2020)

22. F. Orudzhev, S. Ramazanov, D. Sobola, A. Isaev, C. Wang, A. Magomedova, M. Kadiev, K. Kaviyarasu, Nanomaterials, 10, 2183 (2020)

23. F.F. Orudzhev, Sh.M. Ramazanov, A.B. Isaev, N.M.-R. Alikhanov, D. Sobola, M.Yu. Presniakov, K. Kaviyarasu, Materials Today: Proceedings, 36, 364 (2019)

24. Ş. Țălu, S. Solaymani, M. Bramowicz, N. Naseri, S. Kulesza, A. Ghaderi, RSC Advances, 6, 27228 (2016)

25. Ş. Ţălu, S. Stach, J. Zaharieva, M. Milanova, D. Todorovsky, S. Giovanzana, Int J Polym Anal Ch., 19, 404 (2014)

26. Ş. Ţălu, M. Bramowicz, S. Kulesza, A. Ghaderi, V. Dalouji, S. Solaymani, Z. Khalaj, Electron. Mater. Lett., 12, 580 (2016)

27. A. Méndez, Y. Reyes, G. Trejo, K. Stępień, Ş. Ţălu, Microsc. Res. Tech., 78, 1082 (2015)

28. Ş. Ţălu, S. Stach, D. Raoufi, F. Hosseinpanahi, Electron. Mater. Lett., 11, 749 (2015)

29. A.R. Grayeli-Korpi, C. Luna, A. Arman, Ş. Ţălu, Results Phys, 7, 3349 (2017)

30. Ş. Ţălu, S. Stach, A. Mahajan, D. Pathak, T. Wagner, A. Kumar, R.K. Bedi, M. Ţălu, Electron Mater Lett., 10, 719 (2014)

31. Ş. Țălu, Z. Marković, S. Stach, B.T. Marković, M. Țălu, Appl. Surf. Sci., 289, 97 (2014)

32. D. Sobola, Ş. Ţălu, S. Solaymani, L. Grmela, Microsc. Res. Tech., 80, 1328 (2017)

33. Ş, Ţălu, I.A. Morozov, R.P. Yadav, Appl Surf Sci., 484, 892 (2019)

34. F.M. Mwema, E. Akinlabi, P. Oladijo, S. Fatoba, S. Akinlabi, Ş. Țălu, Advances in manufacturing analysis: fractal theory in modern manufacturing. In "Modern Manufacturing Processes", 1st edition, chapter 2, pp. 13-39. DOI: 10.1016/B978-0-12819496-6.00002-6. Editors: K. Kumar, J. Paulo Davim. Woodhead Publishing Reviews: Mechanical Engineering Series, USA, 2020, 246 pages.

35. Ş. Ţălu, A.J. Ghazai, S. Stach, H.A. Hassan, Z. Hassan, M. Ţălu, J. Mater. Sci. Mater. Electron., 25, 466 (2014)

36. A. Jafari, M.H. Alam, D. Dastan, S. Ziakhodadadian, Z. Shi, H. Garmestani, A.S. Weidenbach, Ş. Ţălu, J Mater Sci: Mater Electron, 30, 21185 (2019)

37. A. Jafari, K. Tahani, D. Dastan, S. Asgary, Z. Shi, X.T. Yin, W.D. Zhou, H. Garmestani, Ş. Ţălu, Surf Interfaces, 18, article 100463 (2020)

38. Ş. Țălu, Micro and nanoscale characterization of three dimensional surfaces. Basics and applications. (Napoca Star Publishing House, Cluj-Napoca, Romania, 2015).

39. Ş. Ţălu, M. Bramowicz, S. Kulesza, V. Dalouji, S. Solaymani, S. Valedbagi, Microsc. Res. Tech., 79, 1208 (2016)

40. N. Papež, A. Gajdoš, R. Dallaev, D. Sobola, P. Sedlák, R. Motúz, A. Nebojsa, L. Grmela, Appl Surf Sci., 510, 145329 (2020)

41. N. Papež, L. Škvarenina, P. Tofel, D. Sobola, Proceedings of SPIE - The International Society for Optical Engineering, 10603, 27 (2017) 